\title{
Identifying the origins of high thermoelectric performance in group IIIA elements doped PbS
}

Rui Cheng ${ }^{\mathrm{a}}$, Shiqiang $\mathrm{Hao}^{\mathrm{b}}$, Jun $\mathrm{Li}^{\mathrm{a}}$, Hui Bai ${ }^{\mathrm{a}}$, Sen Xie ${ }^{\mathrm{a}}$, Yue Gong ${ }^{\mathrm{a}}$, Wei $\mathrm{Liu}^{\mathrm{a}}$, Jinsong $\mathrm{Wu}^{\mathrm{a}}$, Gangjian Tan*,a and Xinfeng Tang*,a

a: State Key Laboratory of Advanced Technology for Materials Synthesis and Processing, Wuhan University of Technology, Wuhan 430070, China

b: Department of Materials Science and Engineering, Northwestern University, Evanston, Illinois 60208, United States 

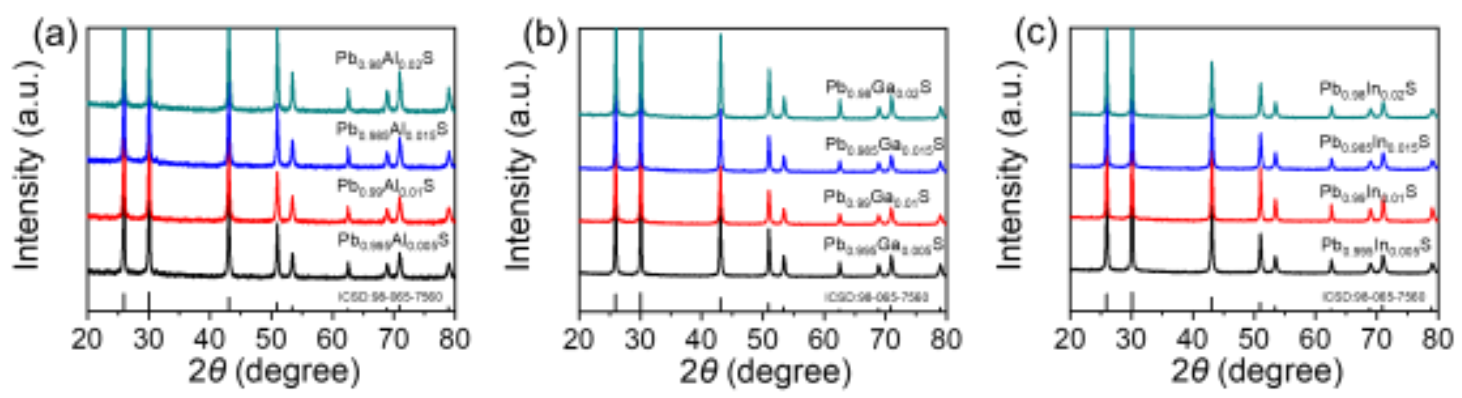

Figure S1. Powder XRD patterns for SPS-processed samples, (a) $\mathrm{Pb}_{1-\mathrm{x}} \mathrm{Al}_{\mathrm{x}} \mathrm{S}$, (b) $\mathrm{Pb}_{1-\mathrm{x}} \mathrm{Ga}_{\mathrm{x}} \mathrm{S},(\mathrm{c}) \mathrm{Pb}_{1-\mathrm{x}} \mathrm{In}_{\mathrm{x}} \mathrm{S},(x=0.5-2 \%)$.

(a)

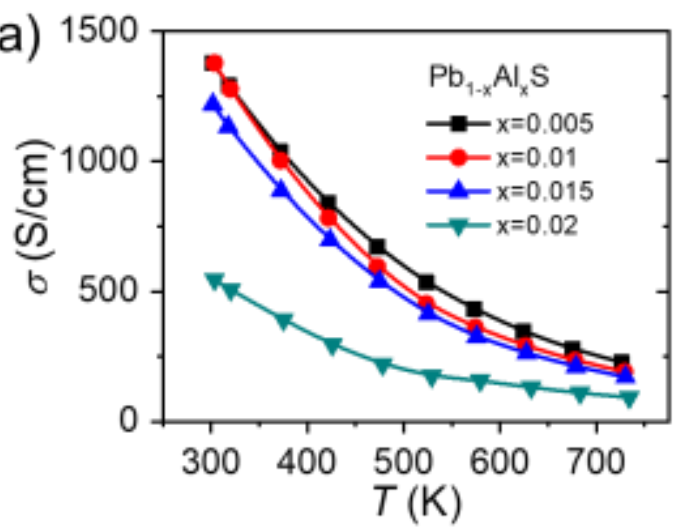

(c)

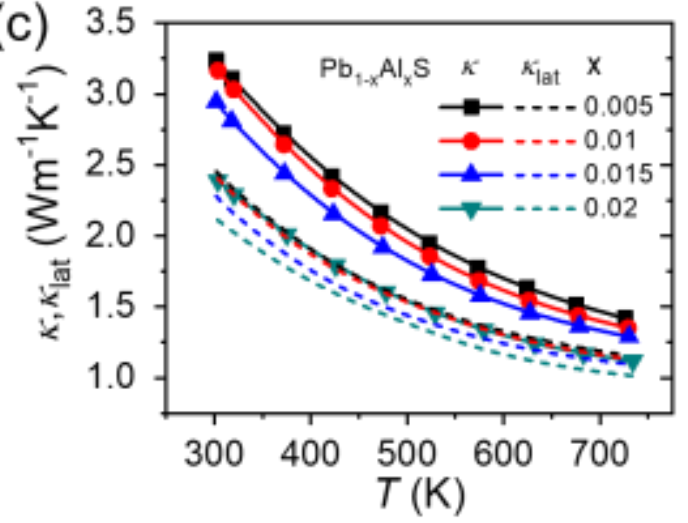

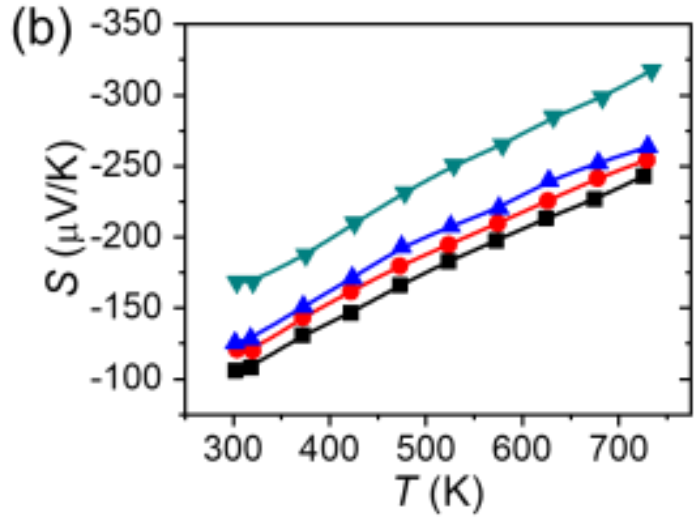

(d)

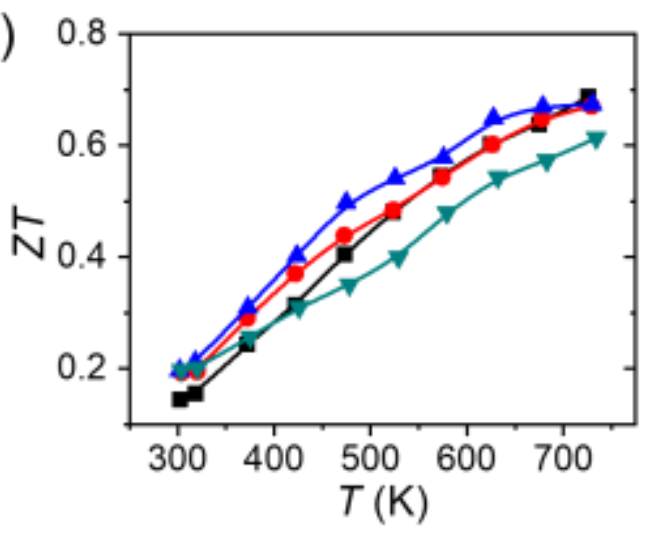

Figure S2. Thermoelectric properties of $\mathrm{Pb}_{1-\mathrm{x}} \mathrm{Al}_{\mathrm{x}} \mathrm{S}$ as a function of temperature: (a) electrical conductivity, (b) Seebeck coefficient, (c) thermal conductivity and lattice thermal conductivity, (d) ZT values. 

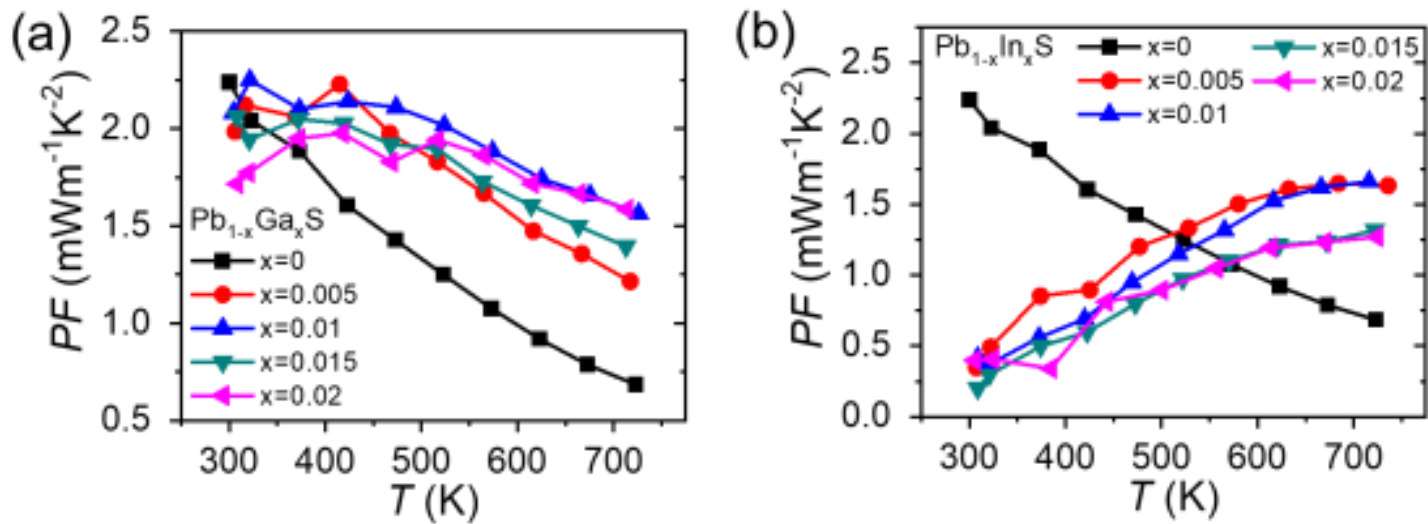

Figure S3. Power factors as a function of temperature: (a) $\mathrm{Pb}_{1-\mathrm{x}} \mathrm{Ga}_{\mathrm{x}} \mathrm{S}$ and (b) $\mathrm{Pb}_{1-\mathrm{x}} \mathrm{In}_{\mathrm{x}} \mathrm{S}$
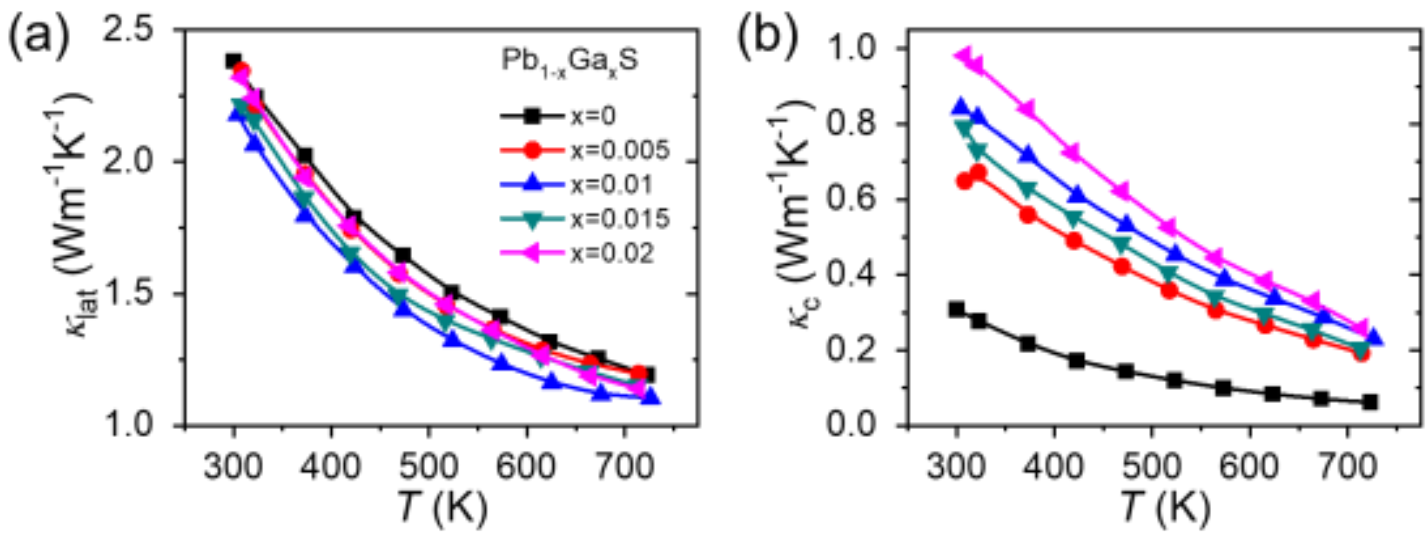

Figure S4. (a) Lattice and (b) carrier thermal conductivity of $\mathrm{Pb}_{1-\mathrm{x}} \mathrm{Ga}_{\mathrm{x}} \mathrm{S}$ as a function of temperature
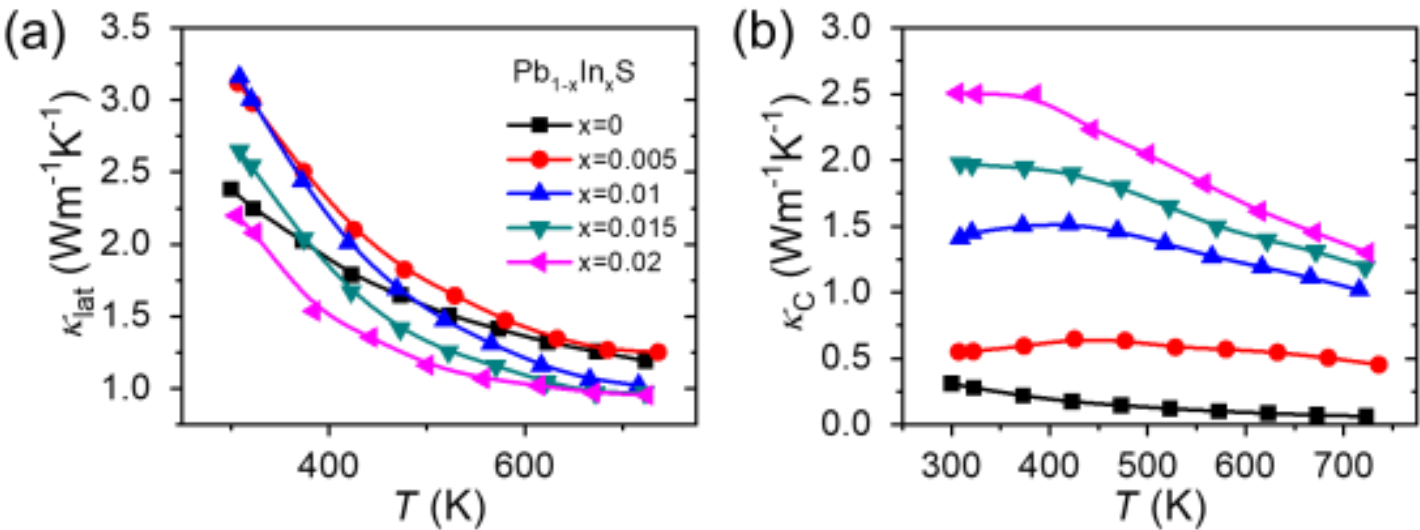

Figure S5. (a) Lattice and (b) carrier thermal conductivity of $\mathrm{Pb}_{1-\mathrm{x}} \mathrm{In}_{\mathrm{x}} \mathrm{S}$ as a function of temperature 